\title{
Cultura e Representações, uma trajetória
}

Sandra Jatahy Pesavento*

Vinte anos de um Programa de Pós-Graduação significa muita coisa. Uma trajetória de vida acadêmica, por certo, marcada por desejos, esforço, lutas em várias frentes, com algumas vitórias e acertos, e outros tantos tropeços, incompreensões e intolerâncias. Mas isto tudo é vida, enfim, vida de pesquisa e de ensino, marcada por paixão e por trabalho. Vinte anos são quase um quarto de século tendo a História por eixo de um trabalho cotidiano. O saldo é positivo e o momento é de pensar o que nos une dentro desta corrente de abordagem da História sob o signo de Clio, nossa musa inspiradora.

Tendo, pessoalmente, trilhado desde o início os caminhos desse Programa, gostaria de abordar um destes vieses que o curso desenvolveu, e com êxito, arrisco a poder dizer: aquele dos estudos, pesquisas e reflexões em torno da cultura e das representações.

* Professora Titular do Departamento de História da UFRGS.

Anos 90, Porto Alegre, v. 13, n. 23/24, p.45-58, jan./dez. 2006 
Acho que essa trajetória conjunta marca um amadurecimento, e é em torno dessa caminhada que quero tecer algumas reflexões.

Começo pelo próprio entendimento da cultura, que mudou nesses vinte anos passados. Nós, da História, aproximamo-nos dos antropólogos por irmos ao encontro desta concepção de cultura como um conjunto de significados partilhados. Logo, a cultura é vista como uma produção social e histórica a se expressar, através do tempo, em valores, modos de ser, objetos, práticas. A cultura é ainda uma forma de leitura e tradução da realidade que se mostra de forma simbólica, ou seja, admite-se que os sentidos conferidos às palavras, às coisas, às ações e aos atores sociais apresentam-se de forma cifrada, portando já um significado e uma apreciação valorativa. A cultura é uma tradução do mundo em significados, não é o reflexo dessa realidade.

Estudos sobre a cultura são, pois, complexos e por si só induzem a uma postura, de certa forma, inter ou transdisciplinar. $\mathrm{O}$ diálogo, sempre enriquecedor para as partes, dá-se, por exemplo, como nesta vizinhança com a Antropologia Cultural, como foi anunciado, ou ainda com a Literatura, a Arte, o Urbanismo, a Cartografia, a Psicanálise e outros tantos domínios da apreensão sensível e científica do mundo. Trabalhar com cultura é estar atento às diferentes falas e formas de dizer a realidade, mas sem jamais perder a sua identidade: é do "lugar" da História que se colocam as questões e se formulam as perguntas dirigidas ao passado. Se uma hierarquia existe entre as diferentes falas e formas de conhecer o mundo, ela é aquela ditada desde o local da construção do problema que indaga sobre a realidade.

Fundamentalmente, há que se registrar vários ganhos nessa trajetória: não mais tem fundamento, hoje, de forma séria e conseqüente, uma postura que possa entender os estudos culturais como independentes do social. Seria possível, objetivamente falando, entender a História sem homens, sem atores, sem ações e sem interação? É cabível, é lógico retirar a vida da História? 
Inconcebível, pois a História estaria negando a sua razão de ser e seus mínimos pressupostos. Desconsidero também, como anacrônicas com este novo século e milênio, as posturas preconceituosas que se aproximam do perfil perverso de um Hermann Göering, que teria dito que toda a vez que ouvia falar em cultura tinha vontade de puxar o revólver!

Creio também não terem mais lugar concepções que abordavam a cultura como resultado mecânico e, a priori, determinado, entendendo-a como integrante da superestrutura e como mero reflexo da infra-estrutura, sem atentar para a historicidade e o arranjo de forças de cada tempo. Essa postura, bem creio, corresponde ao passado e já se tornou, a rigor, um objeto de estudo! Descartadas estão ainda, grosso modo, as concepções que entendiam a cultura como manifestação superior do espírito humano e, portanto, como domínio das elites, viés próprio a uma dita "história intelectual" ou "história das idéias".

Não que as grandes correntes de pensamento ou os nomes mais expressivos deixem de ser estudados, é óbvio. Para o bem e para o mal, o pensamento e a obra dos indivíduos remarcáveis atravessou o tempo, chegando até nós. Mas homens simples, subalternos, primitivos, excluídos, deserdados pela sociedade ou aquém da modernidade da vida também produzem cultura - é claro - como, por exemplo, tão belamente demonstrou, em seus estudos, um E. P. Thompson há muitas décadas... Os homens simples, as vidas anônimas, a banalidade do cotidiano têm lugar nesse âmbito da cultura, tal como a figura excepcional ou o gênio, dependendo da pergunta que o historiador faça ao passado.

Assim, nesse percurso de vinte anos foram também superadas concepções que opunham a cultura erudita à cultura popular, esta ingenuamente concebida como reduto do "autêntico". Faz também bastante tempo que o historiador Carlo Ginzburg veio enriquecer essa proposta, ao introduzir a idéia da "circularidade 
cultural". Traços culturais movem-se por entre os grupos, as camadas ou as classes sociais, permitindo reelaborações contínuas, o que torna mais instigante a análise do passado, vendo o reaproveitamento e a reapropriação dos mesmos valores, que perpassam o tecido do social, em novas criações de sentido. Mais do que isso, se passou a entender que os valores culturais, traduzidos em idéias e imagens, viajam no tempo e no espaço, em reconfigurações e transfigurações de significado.

Já se consegue entender que os estudos da cultura não são uma vertente exclusivamente francesa ou fixada no surgimento da École des Annales, como se fosse possível parar a reflexão historiográfica e conceitual no debate dos anos trinta... Os anos trinta têm seu lugar na historiografia como uma etapa da reflexão que conduziu à História que se pratica no século XXI e, como tal, não podem ser "colados" ou associados de forma idêntica à maneira de pensar e fazer História no mundo de hoje. Mas, enfim, não vou me deter nessa obviedade, passando a uma outra consideração.

É aquela que, por um certo viés, reduz a História Cultural a uma "história francesa". Mesmo que pensadores da França, do século XIX ao XXI, tenham um importante lugar nos estudos da cultura, não há como negar a contribuição ativa e fundamental de uma escola italiana da micro-história, tal como a dos culturalistas alemães, do passado e contemporâneos, ou dos historiadores de língua inglesa daquém e dalém mar. Isto somente para repassar contribuições externas mais relevantes, que encontram ressonância e paralelo na produção historiográfica nacional. O debate e a produção realizam-se em âmbito internacional, pois!

Longe vão também as assertivas herdeiras de uma concepção da belle époque, que entendia a Literatura - e, por extensão, a cultura - como o sorriso da sociedade, como produção para o deleite e a pura fruição do espírito. Logo, esta tal cultura não era séria, não era digna do historiador, era mero passatempo! Hoje se trata, 
antes de tudo, como já foi dito, de pensar a cultura como um conjunto de significados partilhados e construídos pelos homens para explicar o mundo.

Neste ponto, desembocamos em um outro conceito, vital para os estudos da cultura, e que diz respeito às representações. Tratase, digamos, de uma redescoberta dos historiadores na sua maneira de enxergar o mundo e, sobretudo, o passado, proporcionando uma renovação nos domínios de Clio, no que diz respeito a novas questões e problemas, tal como novos temas e objetos. Representações são presentificações de uma ausência, onde representante e representado guardam entre si relações de aproximação e distanciamento.

No início do século XX, os etnólogos Marcel Mauss e Émile Durkheim chamavam a atenção para esta construção de um "mundo paralelo de sinais que se colocava no lugar da realidade", entre os povos primitivos que estudavam. Conceito apropriado pelos historiadores, as representações deram a chave para a análise deste fenômeno presente em todas as culturas ao longo do tempo: os homens elaboram idéias sobre o real, que se traduzem em imagens, discursos e práticas sociais que não só qualificam o mundo como orientam o olhar e a percepção sobre esta realidade.

Ação humana de re-apresentar o mundo - pela linguagem e pela forma, e também pela encenação do gesto ou pelo som -, a representação dá a ver e remete a uma ausência. É, em síntese, "estar no lugar de". Com isto, a representação é um conceito que se caracteriza pela sua ambigüidade, de ser e não ser a coisa representada, compondo um enigma ou desafio que encontrou sua correta tradução imagética na blague pictórica do surrealista René Magritte, como suas telas "Isto não é um cachimbo", ou "Isto não é uma maçã".

Mas - voltamos a insistir neste ponto, por considerar que esta é uma questão que ainda incomoda a muitos - o referente das representações sobre o mundo é sempre o real, o que, no meu 
Cultura e representações, uma trajetória

entender, é quase tautológico. E, nesta medida, o imaginário este sistema de idéias e imagens de representação coletiva que os homens constroem através da história para dar significado às coisas - é sempre um outro real e não o seu contrário. O mundo, tal como o vemos, apropriamo-nos e transformamos é sempre um mundo qualificado, construído socialmente pelo pensamento. Esse é o nosso "verdadeiro" mundo, mundo pelo qual vivemos, lutamos e morremos. O imaginário existe em função do real que o produz e do social que o legitima, existe para confirmar, negar, transfigurar ou ultrapassar a realidade. O imaginário compõe-se de representações sobre o mundo do vivido, do visível e do experimentado, mas também sobre os sonhos, desejos e medos de cada época, sobre o não tangível nem visível, mas que passa a existir e ter força de real para aqueles que o vivenciam.

$\mathrm{E}$, nesse processo de investimento no mundo, de contato do homem com a realidade, um outro conceito impõe-se, em termos culturais, e se situa no próprio âmago da construção social das representações: o das sensibilidades. Capturar as razões e os sentimentos que qualificam a realidade, que expressam os sentidos que os homens, em cada momento da História, foram capazes de dar a si próprios e ao mundo, constituiria o crème de la crème da História, a meta buscada por cada pesquisador! Funcionaria como o reduto mais íntimo da enargheia, esta impressão de vida ou força vital deixada pelos homens no mundo.

As sensibilidades são uma forma de apreensão e de conhecimento do mundo para além do conhecimento científico, que não brota do racional ou das construções mentais mais elaboradas. $\mathrm{Na}$ verdade, se poderia dizer que a esfera das sensibilidades situa-se em um espaço anterior à reflexão, na animalidade da experiência humana, brotada do corpo, como uma resposta ou reação em face da realidade. Como forma de ser e estar no mundo, a sensibilidade traduz-se em sensações e emoções, na reação quase imediata dos 
sentidos afetados por fenômenos físicos ou psíquicos, uma vez em contato com a realidade.

Mas, ao mesmo tempo, as sensibilidades correspondem também às manifestações do pensamento ou do espírito, pela qual aquela relação originária é organizada, interpretada e traduzida em termos mais estáveis e contínuos. Esta seria a faceta mediante a qual as sensações transformam-se em sentimentos, afetos, estados da alma. Ou, em outras palavras, esse seria o momento da percepção, quando os dados da impressão sensorial seriam ordenados e postos em relação com outras experiências e lembranças do "arquivo de memória" que cada um traz consigo.

Assim, cultura e representações, tal como a sensibilidade, não podem estar distantes do conceito de memória. Do mesmo modo como a história é a narrativa que presentifica uma ausência no tempo, a memória também recupera, pela evocação, imagens do vivido. É a propriedade evocativa da memória que permite a recriação mental de um objeto, pessoa ou acontecimento ausente. $\mathrm{E}$, neste ponto, é preciso considerar que todos nós temos um museu imaginário de imagens, transmissoras de uma herança do passado, veiculadas pela memória individual, forjada de acordo com a memória social. Como pensar, pois, em representações, sem ter em conta essa capacidade tão especificamente humana de armazenamento de idéias-imagens que transmitem significados?

Dessa forma, Mnemósine e Clio presidem a reconfiguração imaginária do passado, a trocar sinais, da mneme à anamnese, da proto à metamemória. No jogo entre a lembrança e o esquecimento - as duas faces, contraditórias e combinadas da construção da memória do mundo - há todo um processo de aprendizagem, cultural e histórico. O que somos levados a reter, o que somos induzidos a abandonar, formando lacunas? Silêncios e vazios são um enfrentamento cotidiano para aqueles que buscam entender as razões e os sentimentos que guiavam a vida dos homens do passado. 
Mas pensar em memória e em história induz a referir-se ao sujeito que evoca e ao sujeito que escreve, agente deste ato de presentificar uma ausência. Falemos, pois, de indivíduos, de subjetividades, de trajetórias pessoais, de histórias de vida. Esse é, para todos os efeitos, um viés muito importante, resgatado pelos estudos da cultura. A memória tem seu locus original de realização no indivíduo que rememora, mas todo trabalho de evocação dá-se em acerto com uma memória social. Nesta medida, as reminiscências do eu são trabalhadas com o auxílio das dos outros, tal como a escrita da História, como escrita no tempo, dá-se em palimpsesto com outras escritas precedentes. Mas a cultura avançou mais, nestes caminhos da historiografia: ela fez, dos sujeitos-objetos de seus estudos, os indivíduos, um de seus vieses preferenciais nos últimos anos. Gente anônima ou gente famosa, mas iluminada no seu resgate de vida por outros problemas, passaram a ocupar papel de destaque, dando a medida da utilização da micro-história, da biografia e dos percursos de vida como um caminho promissor.

Todos esses conceitos pressupõem uma atitude de decifração do passado, que nos remete a uma atitude hermenêutica, de decifração e captura de universos de sentido distantes dos nossos. Fazer falar um texto de outra época, revelar a estrangeiridade de um outro tempo - a parafrasear L. P. Hartley - implica uma contraditória relação com o tempo. Por um lado, a proposta de decifração e apreensão de uma alteridade, que faz do passado um outro com relação ao presente. Mas, por outro, revela uma intenção de aprisionar o tempo escoado, salvando-o para o presente, com o que mergulhamos no universo benjaminiano. Historiadores perseguem a meta da epifania, de revelação de um escondido, salvando do esquecimento a memória daquilo que teve lugar um dia.

Cultura, representação, imaginário, sensibilidades, memória e subjetividade, em associação com uma atitude hermeneuta, são assim, pois, conceitos reapropriados pelos investigadores do passado no terreno da cultura, que nesses vinte últimos anos 
construíram uma corrente historiográfica consolidada. Esses conceitos formam como que um marco e guia para a percepção do historiador, a iluminar seu olhar sobre o passado e a possibilitar que ele construa seu tema enquanto objeto, ou seja, problematizando-o, lançando perguntas ao passado, que ele empenha-se para que possam ser respondidas.

Isto posto, eu gostaria de precisar agora algumas questões que foram incorporadas pelos historiadores ao longo desses vinte anos e que se encontram no cerne das discussões atuais. São questões em aberto, em contínuo tecer e retecer de respostas, mostrando a vitalidade das inquietações contemporâneas.

Principio pela questão da temporalidade. E, neste ponto, creio que esses vinte anos passados implicaram uma salutar e oportuna redescoberta dos autores alemães, desde os mais antigos aos mais recentes: Chladenius, Ranke - quem diria! -, Droysen, Dilthey, Benjamin, Koselleck... Em todos eles, o fio condutor de uma preocupação digna de Clio: o tempo. Ou melhor, a identificação de uma multiplicidade de tempos, de uma mutabilidade da ação humana no tempo e de uma também cambiante percepção do tempo, seja na do fazer a história, seja na de enxergar o passado.

Para os historiadores, a reflexão sobre o tempo é crucial, é mesmo a condição sine qua non para o exercício de seu métier especial, que é o de pensar o passado, a temporalidade do escoado, do não visto e não experimentado, que passa por fora da experiência do vivido e que deve ser recuperado pela força do pensamento e pelas habilidades da retórica, apoiadas pela busca de rastros e na sua organização e composição em trama decifrável e coerente.

Pois bem, entendo que essa noção dos vários tempos vai ao encontro da dignificação do ofício do historiador: cabe a ele, desde o presente da escrita, proceder à construção imaginária do passado, contextualizando seu objeto.

Toda a escrita da História implica um tempo do "agora", como anunciou Walter Benjamin, tempo em que as questões 
postas pelo presente lançam-se sobre o passado, buscando respostas. Para Benjamin, a História é um processo inacabado de construção e reconstrução. Walter Benjamin chega mesmo a falar de uma espécie de conjunção de astros, de um momento privilegiado, em que presente e passado encontram-se - o que chama, poeticamente, de "dialética da paralisia" -, e quando é possível que o pesquisador enxergue, no passado, as suas questões e problemas, surpreendendo respostas. Neste "agora de conhecibilidade", surpreende-se o passado com os olhos do presente.

Mas esse "tempo do agora", que implica surpreender a escrita da História desde a sua feitura enquanto narrativa, situando o historiador em sua época, desdobra-se também no agora do acontecimento, objeto desta narrativa. Tempos cambiantes, tempos múltiplos, tempos únicos na sua historicidade de terem tido lugar um dia. Implica, pois, historicizar atores, espaços, sentidos no tempo da pesquisa, o que só é possível pela busca de traços ou fontes e por uma atitude intelectual com relação ao passado.

A essas reflexões sobre as temporalidades, acrescenta-se, de forma especial, a de dois pensadores franceses: Paul Ricoeur e François Hartog. Ricoeur fala-nos da atividade do historiador como uma reconfiguração temporal, como uma operação imaginária de sentido autorizada pelo rastro, por certo, mas que cria, para todos os efeitos, uma nova temporalidade, nem passado nem presente, mas um terceiro tempo, aquele da História. Esse tempo, criado pela narrativa do historiador, toma o lugar do passado e mesmo se substitui a ele. Neste ponto, o conceito de "rastro" apresentado por Ricoeur é, sobretudo, marca essencial de historicidade que se anuncia, de forma visível e/ou tangível, para a recuperação de um tempo escoado. Traço do que foi, "prova" de uma vida ou de uma experiência, o rastro é presença de uma ausência no tempo. Ao encontro dessa linhagem da percepção temporal na História, Hartog acrescenta sua interessante contribuição, quando fala dos regimes de historicidades, mostrando as variáveis cambiantes da construção 
humana do tempo e da sua maneira de configurar e entender o passado.

Tais questões, é claro, remetem a outras tantas, dispostas em cadeia, e que percorrem o universo da cultura. Os tempos múltiplos conduzem, necessariamente, a repensar a própria escrita da História. A historiografia está em alta e com ela a entrada em cena de problemas cruciais para o historiador, como o da verdade e da ficção, ou das aproximações e dos distanciamentos entre a História e a Literatura.

Historiadores, por suposto, perseguem a verdade, pois almejam chegar ao "real acontecido". Mas, lembra Ricoeur, aos historiadores estaria negada esta "pequena alegria", reservada, por exemplo, àquele que rememora: foi lá, foi assim, foi ele, foi então. Aos historiadores, a certeza do reconhecimento e a identificação com a verdade do acontecido dá-se como possibilidade, não como certeza que conforta... Mas, mesmo assim, historiadores não desistem, animados por um desejo de verdade, por uma vontade de "chegar lá". Esse reduto do acontecido, contudo, que o historiador busca reconstruir através dos rastros, é sempre uma atividade de criação, na reiterada tarefa da montagem e composição daqueles traços do passado, cruzados e compostos em nexos de sentido e sobre os quais se tecerá uma narrativa, na busca de desvendar a trama armada. O resultado desse trabalho de pesquisa e escrita é uma versão plausível, possível, verossímil daquilo que foi um dia. Assim, a verdade do acontecido aparece como um horizonte de expectativas e uma meta de chegada.

Entronizada a verossimilhança como pertinente à escrita da História, decorrem outras indagações, presentes no debate atual dos estudos sobre a cultura: comporta a História uma ficção e uma poética? Se atentarmos para o conteúdo atribuído por Natalie Zemon Davis e Carlo Ginzburg, sim. A escrita da História contém ingredientes próprios à ficção, resguardados alguns requisitos: $\mathrm{O}$ de que tudo tenha acontecido, inscrito em rastros ou fontes, e os 
rigores do método. Mas enquanto narrativa, retórica argumentativa, emprego de metáforas e figuras de estilo, emprego de conceitos para iluminar a trama, as escolhas são do historiador. Davis e Ginzburg apontam a ficção como criação a partir do que existe, como conceito para além do verdadeiro e do falso, que anunciam possíveis. Não é possível ainda identificar, como equivalentes, res factae e res fictae, como apontam Koselleck e Jauss.

Nessa medida, introduz-se a polêmica visão de que a ficção é um discurso verossímil que fala do mundo, seja ele do domínio da História ou da Literatura. História e Literatura, como discursos e representações que falam do real, têm com relação a este distintas formas de aproximação. Há, sem dúvida, como bem sabemos, uma diferença essencial: a de que tudo tenha acontecido, condição última da realização da História. Historiadores não criam situações ou fatos e personagens. Podem "descobri-los na poeira dos arquivos, mas não os criam no sentido absoluto. Mas, para a História, a Literatura conta como um rastro de possíveis, como registro de uma sensibilidade no tempo, aquele da escrita da obra". Como refere Jacques Leenhardt, o discurso literário auxilia a História no sentido de ajudar a entender a modalidade temporal do elo social, a unir gerações e indivíduos, permitindo que seja representado, no plano imaginário e ficcional, o teatro do tempo e dos vínculos entre os indivíduos, possibilitando uma entrada no universo do passado.

Em posição similar, de matéria possível para o historiador, encontra-se o mito. $\mathrm{O}$ mito é também uma narrativa, que explica e que revela. $\mathrm{O}$ mito fala de valores e lógicas que dão sentido ao mundo e que respondem às questões fundamentais que os homens põem-se sobre a realidade. Veiculado pela oralidade, constituído de forma anônima, o mito é relato que vem do não-dito, do transmitido de boca em boca, do boato, da lenda, do relato fabuloso que transmite sentidos, onde se divisa uma moral e uma chave para a apreensão da vida. Sem dúvida que o mito fala de forma 
cifrada, mas, ainda assim, o real é o seu referente, pois preside a sua composição. Constituindo um dos integrantes deste sistema de representações sobre o mundo a que se dá o nome de imaginário, o mito revela também verdades, mas verdades simbólicas, que se expressam de forma metafórica e alegórica, dizendo-mostrando para além da palavra e da imagem.

Da Literatura ao mito, caberia estender essas preocupações ao mundo das imagens. As imagens são criação humana dotada de propriedade semântica. Imagens são forma que se dá a ver e a ler, portando significados.

A realidade doa-se ao olhar, que dela grava, na retina, imagens visuais. Estas, contudo, são reelaboradas e construídas como imagens mentais, em associação com o arquivo imagético de memória que cada indivíduo possui, e que é produto de sua experiência de vida, de sua bagagem cultural e profissional, de seu tempo e de seu lugar no espaço e na sociedade. Tais imagens, por força da imaginação, podem ser recuperadas, mesmo diante da ausência do seu referente, o objeto ou ser que as produziu. E podem ser também objetivadas, como imagens criadas materialmente pelo homem, para representar o mundo, através de distintos suportes materiais.

Tal como outras representações sobre o real, as imagens contam para o historiador como portas ou janelas de entrada para o passado, para além do seu valor de documento, que conferiria à imagem o conteúdo de prova. Ce a été, disse Barthes com relação à fotografia. Imagens valem, sobretudo, pelas "verdades do simbólico" que são capazes de transmitir, veiculando razões e sentimentos expressos pelos homens do passado.

$\mathrm{E}$, neste ponto, não me furto de evocar, na rememoração desses vinte anos, algumas idéias-imagens que restam dessa longa caminhada. Tenho certeza que não estou só, neste esforço de reminiscência. A positividade dessas lembranças - as boas - eu as compartilho com os colegas-amigos-parceiros que aqui tenho e com os 
Cultura e representações, uma trajetória

orientandos que hoje, meus colegas-amigos-parceiros também, são mestres e doutores. Afinal, no conjunto da Universidade Federal do Rio Grande do Sul, entre o Programa de Pós-Graduação em História e o Programa de Pós-Graduação em Planejamento Urbano e Regional (PROPUR), eles são ao todo, nesses últimos vinte anos, um número muito expressivo de mestres e doutores...

Um longo caminho, este do percurso de uma proposta de estudar a História através da cultura e das representações do mundo, a mostrar a vitalidade de uma História que se renova no tempo, a relançar novas perguntas, questões e problemas para a decifração do passado. Resta a pergunta final - valeu a pena? - que o poeta maior já respondeu: tudo vale a pena, se a alma não é pequena.

Recebido em 03/08/2006.

Autora convidada. 